\title{
APPROPRIATE ANTIBIOTIC PROPHYLAXIS IN GYNAECOLOGY
}

\author{
Kala Bahuleyan Santha1, Bessy Binu Sam²
}

${ }_{1}^{1}$ Associate Professor, Department of Obstetrics and Gynaecology, Government Medical College, Kottayam, Kerala, India. ${ }^{2}$ Associate Professor, Department of Obstetrics and Gynaecology, Government Medical College, Kottayam, Kerala, India.

\begin{abstract}
BACKGROUND
ABSTRACT

Aseptic techniques have dramatically reduced the incidence of SSI, but it still remains the most common surgical complication affecting 5\% of postoperative patients. Appropriate antibiotic prophylaxis will definitely help in preventing this, indirectly reducing antibiotic resistance and financial cost of surgery. Despite strong evidence, many surgeons are still reluctant to follow antibiotic prophylaxis.
\end{abstract}

\section{MATERIALS AND METHODS}

Objective was to compare the outcome like post-operative complications, need for change in antibiotic and duration of hospital stay after surgery in patients receiving single dose cefazolin prophylaxis as opposed to those receiving cefotaxime and metronidazole postoperatively for 5-7 days. It was a prospective observational study with appropriate statistical analysis.

\section{RESULTS}

Complication rate was comparable in both groups. Antibiotic change needed in both groups due to development of complications. This study concludes that antibiotic prophylaxis must be routinely used in uncomplicated surgeries as it reduces patient morbidity, antibiotic resistance and workload of hospital staff.

\section{CONCLUSION}

Antibiotic prophylaxis must be routinely used in uncomplicated surgeries as it reduces patient morbidity, antibiotic resistance and workload of hospital staff. This study proves that antibiotic prophylaxis is as effective as post-operative antibiotics in preventing postoperative complications.

\section{KEY WORDS}

Antibiotic Prophylaxis, Cefazolin, Surgical Site Infection (SSI), Gynaecological Surgeries.

HOW TO CITE THIS ARTICLE: Santha KB, Sam BB. Appropriate antibiotic prophylaxis in gynaecology. J. Evolution Med. Dent. Sci. 2018;7(53):5581-5586, DOI: $10.14260 /$ jemds/2018/1235

\section{BACKGROUND}

There has been a consistent increase in surgical procedures over the last few decades with an increase in postoperative complications also. Surgical site infections (SSI) continue to be a major problem in all surgical specialities irrespective of advances in asepsis, antimicrobial drugs, sterilization \& operative techniques. SSI is an important cause of increasing cost, postoperative morbidity ${ }^{1,2}$ and mortality and hospitals with all modern amenities and standard preoperative protocols are not free from this. SSI results in expenses of 10 , 000 dollars in excess of usual cost and duration of stay exceeds by 4 days and more. ${ }^{3}$

Most important factors in prevention of postoperative infections are sound judgment and proper technique of surgeon and his team, as well as general health and disease state of patient.4,5 Other factors may also cause infection in clean contaminated surgeries which may be due to air borne microorganisms. ${ }^{6}$

'Financial or Other Competing Interest': None.

Submission 22-11-2018, Peer Review 18-12-2018,

Acceptance 24-12-2018, Published 31-12-2018.

Corresponding Author:

Dr. Kala Bahuleyan Santha

Associate Professor,

Department of Obstetrics and Gynaecology,

Government Medical College,

Kottayam-686008,

Kerala, India.

E-mail: drkalapramod@gmail.com

DOI: $10.14260 /$ jemds/2018/1235

\section{(c) (i) $(9)$}

\section{Background and Rationale}

Infectious complications following gynaecological surgical procedures are a significant source of morbidity and potential mortality. They include urinary tract infection, endometritis, wound infection, vaginal cuff cellulitis, perineal infection and sepsis which can lead to prolonged hospital stay and increased health care costs. Wound complications occur in $20 \%$ patients undergoing abdominal hysterectomy. ${ }^{7}$ Appropriately administered antibiotic prophylaxis reduces the incidence of surgical site infections. All studies recommend antibiotic prophylaxis for clean, clean contaminated and contaminated surgeries. Gynaecological surgeries are considered as clean contaminated wounds as vault is opened and there is access to vagina by which ascending infections can occur. ${ }^{8}$ Also genitourinary system has normal bacterial flora which can turn pathogenic.

There is still hesitation on the part of many operating surgeons to depend solely on antibiotic prophylaxis. Most of them start antibiotics preoperatively and continue for 5-7 days especially in India. Despite many studies proving the effectiveness of antibiotic prophylaxis, it is not a routine practice in many hospitals in India. Many studies have been conducted regarding antibiotic prophylaxis in gynaecological surgeries, but studies comparing antibiotic prophylaxis with postoperative antibiotics are few from India. This study conducted in a government tertiary care centre in India compares the outcome of patients receiving single dose antibiotic prophylaxis as against those receiving routine postoperative antibiotics in uncomplicated gynec surgeries. 


\section{Objectives}

To compare the outcome in patients undergoing elective gynaecological surgeries receiving single dose cefazolin prophylaxis as against those receiving antibiotics postoperatively (Cefotaxime \& Metronidazole) for 5-7 days. Outcomes assessed were-

1. Occurrence of postoperative complications like fever, SSI, UTI, RTI.

2. Change of antibiotic.

3. Duration of hospital stay after surgery.

\section{MATERIALS AND METHODS}

\section{Study Design}

Prospective Observational study.

\section{Study Period}

12 months from (April 2012- March 2013).

\section{Study Procedure}

Gynaecological procedures selected were laparoscopy, myomectomy, cystectomy, abdominal or vaginal hysterectomy, hysterectomy with salpingo-ovariotomy etc. Patients were selected using the following inclusion and exclusion criteria.

\section{Inclusion Criteria}

Elective gynaecological surgeries without any comorbidities and systemic illness like diabetes, anaemia, bronchial asthma, COPD, C/C liver and renal diseases, which could delay wound healing.

\section{Exclusion Criteria}

1. Complicated gynaecological surgeries.

2. Surgeries with vertical skin incision.

3. Malignancies.

The study group was divided into two groups-

\section{Group 1}

Patients receiving single prophylactic dose of IV cefazolin before surgery.

\section{Group 2}

Age. BMI and surgery matched patients who receive intravenous cefotaxime and metronidazole pre and postoperatively for 5-7 days.

After taking informed consent, using a proforma, details were collected from the patient belonging to each group. Each patient is followed up till discharge. Development of following complications assessed in postoperative period

1. Postoperative fever or febrile morbidity: - Defined as temperature $>100.4{ }^{0} \mathrm{~F}$ recorded on at least 2 successive occasions 6 hours apart excluding first 24 hours after surgery.

2. Surgical site Infection- in the first postoperative week. Involves skin and subcutaneous tissue with any of the following.

a. Purulent discharge.

b. Organism isolated from fluid / tissue of superficial incision.

c. Wound opened by surgeon for drainage.

d. At least one sign of inflammation. e. Treating surgeon declares wound as infected.

1. Urinary tract infection- when patient complains of dysuria and pus cells present.

2. Respiratory tract infection- productive cough. Confirmation by sputum culture not needed.

3. Addition of new antibiotic for fever, respiratory infection, UTI or SSI.

4. Prolonged hospital stay.

\section{Analysis}

After the completion of data collection, it was properly coded and entered appropriately into soft ware- Microsoft excel. The compiled data was transferred to software SPSS 16 for further analysis. Association between variables tested using Chi square test and Fishers Exact test. The level of significance taken as $\mathrm{p}$ value $<0.05$ and highly significant as p- value $<0.01$

\section{RESULTS}

A total of 150 gynaecological surgeries were taken for the study, such that 75 patients were given cefazolin prophylaxis \& the next 75 patients were given cefotaxime \& metronidazole. The gynaecological surgeries taken for the study were-

1. Laparoscopy - 24 patients $(16 \%)$

2. Myomectomy -16 patients $(10.7 \%)$

3. TAH - 16 patients $(10.7 \%)$

4. $\mathrm{TAH}+\mathrm{BSO}-50$ patients $(33.3 \%)$

5. Cystectomy/Salpingo oophorectomy - 14 patients $(9.3 \%)$

6. VH - 30 patients $(20 \%)$

\section{Complications in Surgeries}

It is very evident from the table below that laparoscopy patients developed no post operative complications. $25 \%$ of myomectomy patients developed fever \& no other complications. $12.5 \%$ of patients who underwent TAH developed fever \& only 1 patient (6.25\%) developed RTI. Post-op fever \& SSI occurred in $8 \%$ each of the patients who underwent TAH + BSO \& 1 patient $(2 \%)$ developed UTI. Patients who underwent cystectomy or salpingooophorectomy had only 1 case of nost-op fever (7.14\%). Vaginal hysterectomy patients developed fever in $16.67 \%$ patients, UTI in $6.67 \%$ cases \& $3.33 \%$ i.e. 1 patient developed RTI.

\begin{tabular}{|c|c|c|c|c|c|c|c|}
\hline \multirow{2}{*}{ Surgery } & \multicolumn{5}{|c|}{ Complications } & \multirow{2}{*}{ Total } & \multirow{2}{*}{$\%$} \\
\hline & Nil & Fever & SSI & UTI & RTI & & \\
\hline Laparoscopy & 24 & 0 & 0 & 0 & 0 & 24 & 16 \\
\hline Myomectomy & 12 & 4 & 0 & 0 & 0 & 16 & 10.7 \\
\hline TAH & 13 & 2 & 0 & 0 & 1 & 16 & \begin{tabular}{|l|}
10.7 \\
\end{tabular} \\
\hline TAH with BSO & 41 & 4 & 4 & 1 & 0 & 50 & 33.3 \\
\hline $\begin{array}{c}\text { Ovarian } \\
\text { Cystectomy }\end{array}$ & 13 & 1 & 0 & 0 & 0 & 14 & 9.3 \\
\hline $\begin{array}{c}\text { Vaginal } \\
\text { Hysterectomy }\end{array}$ & 22 & 5 & 0 & 2 & 1 & 30 & 20 \\
\hline Total & 125 & 16 & 4 & 3 & 2 & 150 & \\
\hline $\begin{array}{c}\text { Percentage } \\
\text { Complication }\end{array}$ & $\begin{array}{c}83.3 \\
\%\end{array}$ & $\begin{array}{c}10.67 \\
\%\end{array}$ & $\begin{array}{c}2.67 \\
\%\end{array}$ & $\begin{array}{c}2 \\
\%\end{array}$ & $\begin{array}{c}1.33 \\
\%\end{array}$ & & \\
\hline
\end{tabular}

Table 1. Surgery * Complications Cross-Tabulation

\section{Analysing each Surgery Separately}

For Laparoscopy, 24 patients were taken for the study. 12 were given cefazolin \& the next 12 patient's cefotaxime. None 
of the patients who underwent laparoscopy developed complications or required a change of antibiotic, irrespective of whether they had received cefazolin prophylaxis or cefotaxime post-operatively. But cefazolin administration helped in reducing the hospital stay. All of the 12 patients could be discharged on the $2^{\text {nd }}$ or $3^{\text {rd }}$ post-operative day whereas the other 12 patients were hospitalised for the completion of antibiotic course. This is statistically significant, p value- $0.00 \&$ chi square- 24 .

\begin{tabular}{|c|c|c|c|}
\hline \multirow{2}{*}{ Antibiotic } & \multicolumn{2}{|c|}{ Discharged on POD } & \multirow{2}{*}{ Total } \\
\cline { 2 - 3 } & $<\mathbf{4}$ & $\mathbf{4 - 6}$ & \\
\hline 1 & $12(100 \%)$ & 0 & $12(100 \%)$ \\
\hline 2 & 0 & $12(100 \%)$ & $12(100 \%)$ \\
\hline Total & $\mathbf{1 2}(\mathbf{5 0} \%)$ & $\mathbf{1 2}(\mathbf{5 0} \%)$ & $\mathbf{2 4}(\mathbf{1 0 0 \% )}$ \\
\hline \multicolumn{3}{|l}{ Table 2. Antibiotic ${ }^{*}$ Discharged on POD-Laparoscopy } \\
\hline
\end{tabular}

Chi square $-24 \mathrm{p}$ value -0.00

Analysing the myomectomy patients, the only complication that occurred was post-op fever for 4 patients (25\%). Of this 1 patient had received cefazolin, while the other 3 had cefotaxime \& metronidazole. Administration of cefotaxime \& metronidazole has no statistical significance in preventing post op fever for myomectomy patients. P value 0.248 . Chi square -1.33 .

\begin{tabular}{|c|c|c|c|}
\hline \multirow{2}{*}{ Antibiotic } & \multicolumn{2}{|c|}{ Complication } & \multirow{2}{*}{ Total } \\
\cline { 2 - 3 } & Nil & Fever & \\
\hline 1 & $7(87.5 \%)$ & $1(12.5 \%)$ & $8(100 \%)$ \\
\hline 2 & $5(62.5 \%)$ & $3(37.5 \%)$ & $8(100 \%)$ \\
\hline Total & $\mathbf{1 2 ( 7 5 \% )}$ & $\mathbf{4}(\mathbf{2 5} \%)$ & $\mathbf{1 6}(\mathbf{1 0 0} \%)$ \\
\hline \multicolumn{4}{|c|}{ Table 3. Myomectomy } \\
\hline
\end{tabular}

Chi square -1.33 p value -0.248 .

All the patients who underwent myomectomy were discharged on the 5 or 6 post operative day, except one patient. She had received cefotaxime $\&$ metronidazole post operatively. She developed fever on $4^{\text {th }}$ post-op day $\&$ newer antibiotics were started. Hence, she could be discharged only on the $8^{\text {th }}$ post-op day. 2 other patients in the cefotaxime, metronidazole group also had fever, but they got better with continuation of the same drugs parenterally. One patient among the cefazolin group also developed fever \& new antibiotic was added, but there was no prolongation of hospital stay.

\begin{tabular}{|c|c|c|c|}
\hline \multirow{2}{*}{ Antibiotic } & \multicolumn{2}{|c|}{ Discharged on POD } & \multirow{2}{*}{ Total } \\
\cline { 2 - 3 } & $\mathbf{4 - 6}$ & $>6$ & \\
\hline 1 & $8(100 \%)$ & 0 & \\
\hline 2 & $7(87.5 \%)$ & $1(12.5 \%)$ & \\
\hline Total & $15(93.75 \%)$ & $1(6.25 \%)$ & \\
\hline \multicolumn{3}{|c|}{ Table 4. Antibiotic * Discharged on POD } \\
\hline
\end{tabular}

\begin{tabular}{|c|c|c|c|}
\hline \multirow{2}{*}{ Antibiotic } & \multicolumn{2}{|c|}{ Antibiotic Change } & \multirow{2}{*}{ Total } \\
\cline { 2 - 3 } & No & Yes & \\
\hline 1 & $7(87.5 \%)$ & $1(12.5 \%)$ & \\
\hline 2 & $7(87.5 \%)$ & $1(12.5 \%)$ & \\
\hline Total & $14(87.5 \%)$ & $2(12.5 \%)$ & \\
\hline \multicolumn{3}{|c|}{ Table 5. Antibiotic * Antibiotic Change } \\
\hline
\end{tabular}

Both the group had change of antibiotic in 1 patient each. Hospital stay was prolonged in one patient in the cefotaximemetronidazole group only \& not for the cefazolin group, but there is no statistical significance in the duration of hospital stay among the 2 antibiotic groups. P value $-0.302 \&$ chi square -1.067 .

\begin{tabular}{|c|c|c|c|}
\hline \multirow{2}{*}{ Change } & \multicolumn{2}{|c|}{ Discharged on POD } & \multirow{2}{*}{ Total } \\
\cline { 2 - 3 } & $\mathbf{4 - 6}$ & $>\mathbf{6}$ & \\
\hline No & $14(100 \%)$ & 0 & $14(100 \%)$ \\
\hline Yes & $1(50 \%)$ & $1(50 \%)$ & $2(100 \%)$ \\
\hline Total & $15(93.75 \%)$ & $1(6.25 \%)$ & $16(100 \%)$ \\
\hline \multicolumn{3}{|c|}{ Table 6. Antibiotic Change * Discharged on POD } \\
\hline
\end{tabular}

Chi square $-1.067 \mathrm{p}$ value -0.302 .

\section{TAH (Total Abdominal Hysterectomy)}

The cefazolin group who underwent TAH, 1 patient developed RTI \& another 1 patient fever. The cefotaximemetronidazole group had only 1 patient with complication that is fever. This is not statistically significant as $p$ value is 0.584 \& chi square is 1.077 .

\section{Change of Antibiotic}

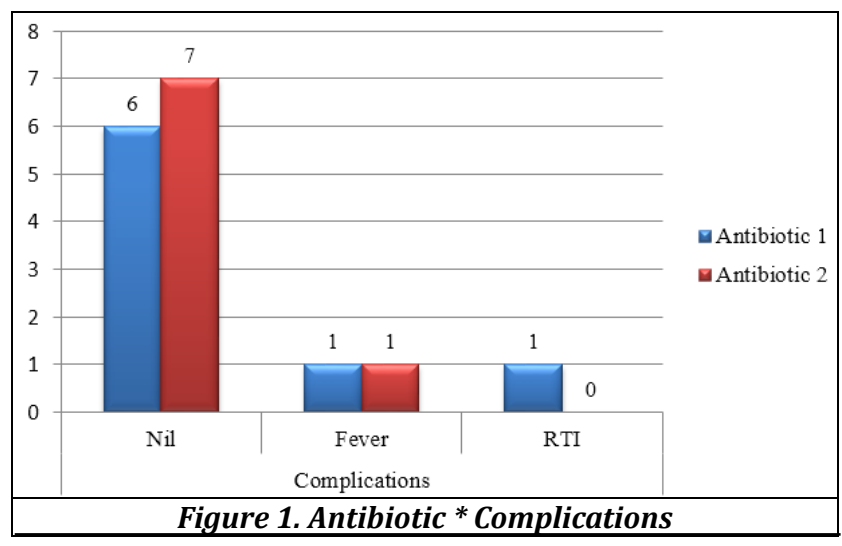

Antibiotic change was required only for the cefazolin group that is for 2 patients whereas none in the cefotaximemetronidazole group required antibiotic change. But as per the p value (0.131) \& chi square (2.286) there is no statistical significance.

\begin{tabular}{|c|c|c|c|}
\hline \multirow{2}{*}{ Antibiotic } & \multicolumn{2}{|c|}{ Change } & \multirow{2}{*}{ Total } \\
\cline { 2 - 3 } & No & Yes & \\
\hline 1 & $6(75 \%)$ & $2(25 \%)$ & $8(100 \%)$ \\
\hline 2 & $8(100 \%)$ & 0 & $8(100 \%)$ \\
\hline Total & $14(87.5 \%)$ & $2(12.5 \%)$ & $\begin{array}{c}16 \\
(100 \%)\end{array}$ \\
\hline \multicolumn{3}{|c|}{ Table 7. Antibiotic* Antibiotic Change } \\
\hline
\end{tabular}

Hospital stay was prolonged only for 1 patient \& she had received postoperative cefotaxime-metronidazole. That patient had post-op fever \& hence the same drugs were continued parenterally for 7 days. Every patient among the cefazolin group had been discharged on the $5^{\text {th }}$ or $6^{\text {th }}$ post-op day. Though antibiotic was changed following development of complications hospital stay was not prolonged. Statistically this is not significant, p value 0.302 \& chi-square -1.067 . 


\begin{tabular}{|c|c|c|c|}
\hline \multirow{2}{*}{ Antibiotic } & \multicolumn{2}{|c|}{ Discharged on POD } & \multirow{2}{*}{ Total } \\
\cline { 2 - 3 } & $\mathbf{4 - 6}$ & $>\mathbf{6}$ & \\
\hline 1 & $8(100 \%)$ & 0 & $8(100 \%)$ \\
\hline 2 & $7(87.5 \%)$ & $1(12.5 \%)$ & $8(100 \%)$ \\
\hline Total & $15(93.75 \%)$ & $1(6.25 \%)$ & $16(100 \%)$ \\
\hline \multicolumn{3}{|c|}{ Table 8. Antibiotic* Discharged on POD } \\
\hline
\end{tabular}

Both the groups who underwent TAH+BSO, developed complications in the post-op period. Among the 25 patients in cefazolin group, 21 patients had no complications, 2 patients developed fever, 1 patient SSI \& 1 patient UTI. The cefotaxime-metronidazole group, on the other hand, had 20 patients without complications ${ }^{\wedge}$ patients with fever \& 3 patients had SSI. Statistically, p value- $0.567 \mathrm{Si}$ chi square2.024 , shows no evidence to favour of any antibiotic group.

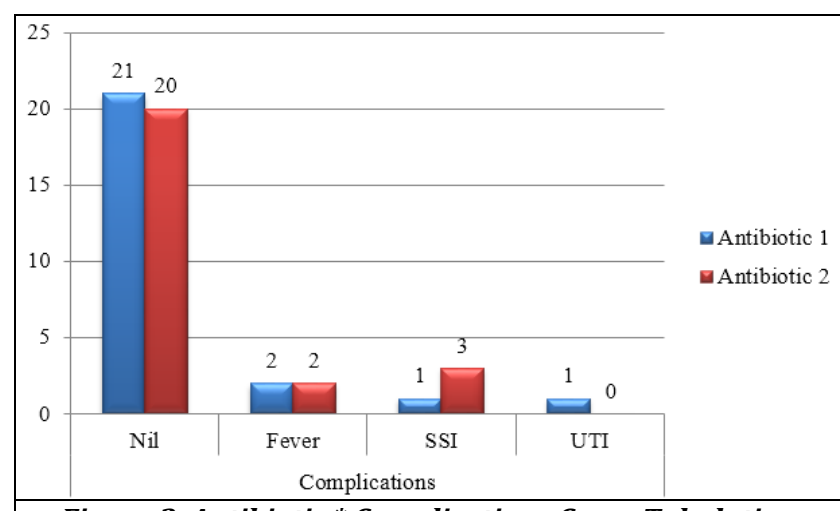

Figure 2. Antibiotic * Complications Cross-Tabulation

Evaluation for change of antibiotic \& prolongation of hospital stay, shows 4 patients in the cefazolin group \& 3 patients in the cefotaxime-metronidazole group. All patients who needed change in antibiotic could be discharged later than usual. No statistical significance has been noted, $\mathrm{p}$ value $-0.684 \&$ chi square -0.166 .

\begin{tabular}{|c|c|c|c|}
\hline \multirow{2}{*}{ Antibiotic } & \multicolumn{2}{|c|}{ Change } & \multirow{2}{*}{ Total } \\
\cline { 2 - 3 } & No & Yes & \\
\hline 1 & $21(84 \%)$ & $4(16 \%)$ & $25(100 \%)$ \\
\hline 2 & $22(88 \%)$ & $3(12 \%)$ & $25(100 \%)$ \\
\hline Total & $\mathbf{4 3}(\mathbf{8 6} \%)$ & $\mathbf{7 ( 1 4 \% )}$ & $\mathbf{5 0}(100 \%)$ \\
\hline \multicolumn{3}{|c|}{ Table 9. Change of Antibiotic } \\
\hline
\end{tabular}

\begin{tabular}{|c|c|c|c|}
\hline \multirow{2}{*}{ Antibiotic } & \multicolumn{2}{|c|}{ Discharged on POD } & \multirow{2}{*}{ Total } \\
\cline { 2 - 3 } & $\mathbf{4 - 6}$ & $>\mathbf{6}$ & \\
\hline 1 & $21(84 \%)$ & $4(16 \%)$ & $25(100 \%)$ \\
\hline 2 & $22(88 \%)$ & $3(12 \%)$ & $25(100 \%)$ \\
\hline Total & $\mathbf{4 3 ( 8 6 \% )}$ & $\mathbf{7 ( 1 4 \% )}$ & $\mathbf{5 0}(100 \%)$ \\
\hline Table 10. Antibiotic * Discharged on POD Cross-Tabulation \\
\hline
\end{tabular}

As far as cystectomy patients are concerned, there were 7 patients each in the cefazolin group \& the cefotaximemetronidazole group. 1 patient in the latter group had postop fever \& prolongation of hospital stay. Chi square 1.077 \& p value 0.299 . The cefazolin group had no complications or prolongation of hospital stay. None of the patients who underwent cystectomy needed antibiotic change.

\begin{tabular}{|c|c|c|c|}
\hline \multirow{2}{*}{ Antibiotic } & \multicolumn{2}{|c|}{ Complications } & \multirow{2}{*}{ Total } \\
\cline { 2 - 3 } & $\mathbf{0}$ & $\mathbf{1}$ & \\
\hline 1 & $7(100 \%)$ & 0 & $7(100 \%)$ \\
\hline 2 & $6(85.7 \%)$ & $1(14.3 \%)$ & $7(100 \%)$ \\
\hline Total & $\mathbf{1 3 ( 9 2 . 8 5 \% )}$ & $\mathbf{1 ( 7 . 1 5 \% )}$ & $\mathbf{1 4}(\mathbf{1 0 0 \% )}$ \\
\hline
\end{tabular}

Table 11. Antibiotic * Complications Cross-Tabulation

\begin{tabular}{|c|c|c|c|}
\hline \multirow{2}{*}{ Antibiotic } & \multicolumn{2}{|c|}{ Antibiotic Change } & \multirow{2}{*}{ Total } \\
\cline { 2 - 4 } & No & Yes & \\
\hline 1 & $7(100 \%)$ & 0 & $7(100 \%)$ \\
\hline 2 & $7(100 \%)$ & 0 & $7(100 \%)$ \\
\hline Total & $14(100 \%)$ & 0 & $14(100 \%)$ \\
\hline \multicolumn{4}{|c}{ Table 12. Antibiotic * Antibiotic Change } \\
\hline
\end{tabular}

\begin{tabular}{|c|c|c|c|}
\hline \multirow{2}{*}{ Antibiotic } & \multicolumn{2}{|c|}{ Discharged on POD } & \multirow{2}{*}{ Total } \\
\cline { 2 - 3 } & $\mathbf{4 - 6}$ & $>\mathbf{6}$ & \\
\hline 1 & $7(100 \%)$ & 0 & $7(100 \%)$ \\
\hline 2 & $6(85.7 \%)$ & $1(14.3 \%)$ & $7(100 \%)$ \\
\hline Total & $13(92.9 \%)$ & $\mathbf{1}(7.1 \%)$ & $14(100 \%)$ \\
\hline \multicolumn{4}{|c}{ Table 13. Antibiotic* Discharged on POD } \\
\hline
\end{tabular}

The vaginal hysterectomy patients have developed more complications than the other gynaecological surgery group. The cefazolin group had 3 cases of fever $(20 \%)$ and 1 case each of UTI \& RTI (6.67\%). The cefotaxime-metronidazole group had 2 cases of fever (13.35\%) \& 1 case of UTI (6.67\%). Both the antibiotics have no significant superiority in preventing complications after surgery. Chi square - 1.382 \&p value -0.710 .

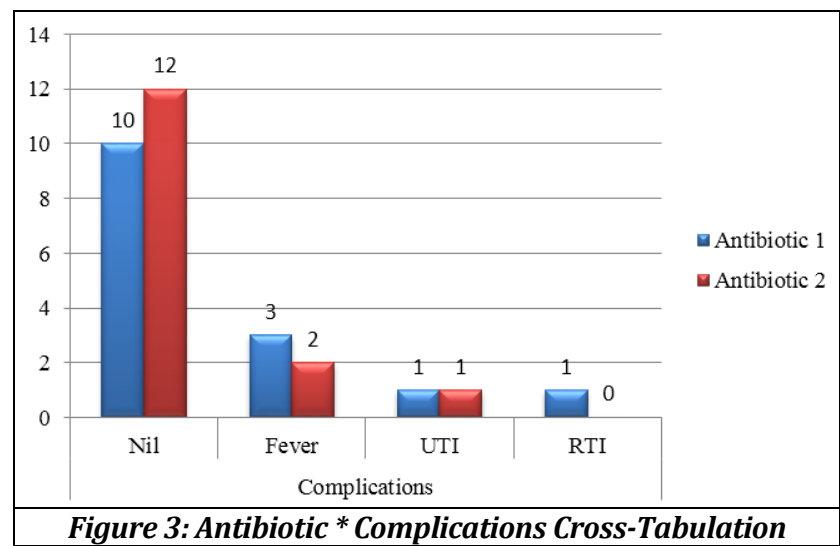

The cefazolin group had to change the antibiotic in 5 patients $(33.34 \%)$, whereas the cefotaxime-metronidazole group had to change antibiotic in only 1 patient (6.67\%). Though it is not statistically significant, chi square - $3.33 \& \mathrm{p}$ value -0.068 in this group, the cefazolin group had required maximum number of antibiotic changes for vaginal hysterectomy. 


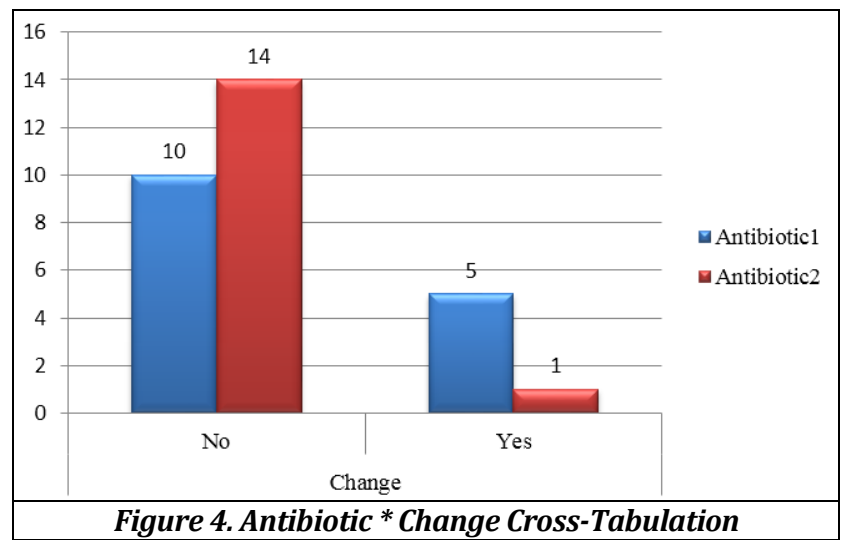

Hospital stay was prolonged in $20 \%$ cases of cefazolin group i.e. 3 cases. In cefotaxime-metronidazole only 1 patient had to stay in hospital for $>6$ days i.e. $6.67 \%$. chi square being $1.184 \&$ p value $(0.283)$, it is not statistically significant.

\begin{tabular}{|c|c|c|c|}
\hline \multirow{2}{*}{ Antibiotic } & \multicolumn{2}{|c|}{ Discharged on POD } & \multirow{2}{*}{ Total } \\
\cline { 2 - 3 } & $\mathbf{4 - 6}$ & $\mathbf{> 6}$ & \\
\hline 1 & $12(80 \%)$ & $3(20 \%)$ & $15(100 \%)$ \\
\hline 2 & $14(93.3 \%)$ & $1(6.7 \%)$ & $15(100 \%)$ \\
\hline Total & $\mathbf{2 6}(\mathbf{8 6 . 7 \% )}$ & $\mathbf{4}(13.3 \%)$ & $\mathbf{3 0}(\mathbf{1 0 0 \% )}$ \\
\hline \multicolumn{3}{|c|}{ Table 14. Antibiotic ${ }^{*}$ Discharged on POD } \\
\hline
\end{tabular}

\section{DISCUSSION}

As shown in the results elective gynaecological surgeries including laparoscopy taken for the study. All obese patients were excluded as BMI influence the outcome of surgery in terms of an increased rate of SSI.9,10 Also patients with diabetes and anaemia which can lead to delayed wound healing were excluded from the study.

The purpose of antibiotic prophylaxis is not to sterilize tissues but to reduce colonization pressure of micro organisms introduced at the time of operation to a level that the patient's immune system is able to overcome. ${ }^{11}$ Prophylaxis does not prevent infection caused by postoperative contamination. Prophylactic antibiotic must cover the organisms present in tissue at the time of intial incision. Therapeutic concentrations must be maintained throughout the procedure. Level 1 evidence on antibiotic prophylaxis states that preoperative dose of antibiotic is as effective as a full 5-day course in uncomplicated procedures. $^{12-15}$ It must be given 1 hour prior to incision. Prophylaxis indicated for all elective procedures in which incision will be closed in the operating room.

On discussing individual cases separately, in our study there were no postoperative complications in laparoscopic patients in both arms, but Cefazolin group could be discharged early as further antibiotic doses not needed. This is significant factor in reducing hospital stay and workload of hospital staff. A randomized non-blind trial of 450 women undergoing laparoscopy found no difference in infection rates between those who received a single dose of Cefazolin and those who did not.16 Laparoscopy without hysterectomy considered as clean surgeries as genital tract not opened and antibiotic prophylaxis ideal for it. But according to level $1 \mathrm{E}$ evidence suggest antibiotic prophylaxis not recommended for laparoscopy that does not enter uterus or vagina.

In abdominal hysterectomy, numerous meta analysis have explored the safety of antibiotic prophylaxis. Tanos \&
Rojansky in 1994 compared 17 trials that used single dose or up to 24 hours intramuscular or intravenous cephalosporins, which showed a significant reduction in the incidence of infection in the treatment group. They concluded that a single dose of first- or second-generation cephalosporin was effective. Another randomized trial comparing amoxicillinclavulanic acid with cefazolin showed significant superiority to cefazolin in reducing post operative infection. ${ }^{17}$ In our study only $12.5 \%$ patients who underwent T AH developed fever and only one patient developed RTI. Post operative fever and SSI occurred in $8 \%$ patients who underwent TAH with BSO and one patient developed UTI. Level 1 A evidence on hysterectomy recommends a single dose of firstgeneration cephalosporin. If an abdominal procedure is lengthy, or blood loss $>1500 \mathrm{ml}$, an additional dose of prophylactic antibiotic may be given 3-4 hours after the initial dose (3 C). This was followed in our study also.

In our study vaginal hysterectomy patients developed more complications than other gynaecological surgery groups. The Cefazolin group had 3 cases of fever and 1 case of UTI \& RTI. The Cefotaxime group had 2 cases of fever and 1 case of UTI. Both the antibiotics have no significant superiority in preventing complications after surgery. This was against a Cochrane review that suggested that vaginal hysterectomy results in fewer unspecified infections or febrile episodes than abdominal hysterectomy. ${ }^{18}$ Also cefazolin group had to change the antibiotic in 5 patients and Taxim-metronidazole group had to change the antibiotic in one patient. There is level $3 \mathrm{~B}$ evidence that all patients undergoing surgery for pelvic organ prolapse must receive prophylactic antibiotics.

On analysing results, $16 \%$ patients who received cefazolin prophylaxis had to be started on new course antibiotics due to post-operative complications while only $6.67 \%$ in Taxim group was started. This is not statistically significant. This increase in antibiotic change for cefazolin group was partly because of anxiety on the part of treating doctor and new antibiotic added at the slightest indication like erythema in the cefazolin group. Among the cefazolin group, vaginal hysterectomy patients needed maximum number of antibiotic changes.

Administration of cefazolin helped in reducing hospital stay for 12 patients which is statistically significant, $p$ value being 0.001 and chi-square 13.09. On analysing cases separately also, post-operative complications were less for cefazolin group. Analysing myomectomy patients, only complication encountered was postoperative fever for 4 patients. Of this one patient was on cefazolin group and other three had taxim and metronidazole.

Thus, we can see that despite administration of cefazolin prophylaxis, patients did not have significant complications as compared to Taxim group. Addition of antibiotic in the cefazolin group has not prolonged the hospital stay as other groups. The follow up of outcomes showed that there was no added advantage of post-operative antibiotics over antibiotic prophylaxis.

\section{CONCLUSION}

Antibiotic prophylaxis has long been established as effective in preventing post-operative complications especially SSI. The reluctance to depend on prophylaxis alone is due to limitation of sterilization techniques and aseptic precautions. 
In addition to antibiotic prophylaxis, all factors that affect infectious risk reduction must be reviewed. Sterile surgical fields must be ensured, and ongoing quality assessment of sterilization techniques, air ventilation and post-operative wound care needed. This study proves that antibiotic prophylaxis is as effective as post-operative antibiotics in preventing postoperative complications. Post-operative antibiotics should not be an excuse for laxity in aseptic precautions \& surgical techniques.

\section{Recommendations}

1. Antibiotic prophylaxis preferred in uncomplicated surgeries and all hospitals must have a protocol for antibiotic prophylaxis.

2. Postoperative antibiotics preferred only if there are complications intra or postoperatively.

3. There should be strict adherence to aseptic techniques and minimum handling of tissues.

\section{Limitations}

1. Post discharge surveillance was not done in this study.

2. Patients were not matched with respect to operating surgeon.

3. Blinding of treating surgeon was not done. This could have prevented overanxious treatment in cefazolin group.

\section{REFERENCES}

[1] Ortega G, Rhee DS, Papandria DJ, et al. An evaluation of surgical site infections by wound classification system using the ACS-NSQIP. J Surg Res 2012;174(1):33-8.

[2] Campbell DA Jr, Henderson WG, Englesbe MJ, et al. Surgical site infection prevention: the importance of operative duration and blood transfusion--results of the first American College of Surgeons-National Surgical Quality Improvement Program Best Practices Initiative. J Am Coll Surg 2008;207(6):810-20.

[3] Boltz MM, Hollenbeak CS, Julian KG, et al. Hospital costs associated with surgical site infections in general and vascular surgery patients. Surgery 2011;150(5):934-42.

[4] Nichols RL. Postoperative wound infection. I. N Engl J Med 1982;307:1701-2.

[5] Nichols RL. Surgical wound infection. Am J Med 1991;91(Suppl 3):S54-S64.
[6] Nichols RL. Techniques known to prevent postoperative wound infection. Infection Control 1982;3(1):34-7.

[7] Clarke-Pearson DL, Geller EJ. Complications of hysterectomy. Obstet Gynecol 2013;121(3):654-73.

[8] Mudholkar AS, Tarlekar VS, Wagh GN. Study of prophylactic single dose of antibiotic in obstetric \& gynaecological procedures in low risk patients. Indian Journal of Applied Research 2013;3:284.

[9] Schneid-Kofman N, Sheiner E, Levy A, et al. Risk factors for wound infection following cesarean deliveries. International Journal of Gynaecology \& Obstetrics 2005;90(1):10-5.

[10] Canturk Z, Canturk NZ, Cetinarslan B, et al. Nosocomial infections and obesity in surgical patients. Obesity Research 2003;11(6):769-75.

[11] Mangram AJ, Horan TC, Pearson ML, et al. Guideline for prevention of surgical site infections, 1999. Centers for Disease Control and Prevention (CDC) Hospital Infection Control Practices Advisory Committee. Am J Infect Control 1999;27(2):97-132.

[12] Antibiotic prophylaxis for surgery. Treatment guidelines. The Medical Letter 2004:2(20):27-32.

[13] Antimicrobial prophylaxis in surgery. The Medical Letter 2001;43:92-8.

[14] ASHP therapeutic guidelines on antimicrobial prophylaxis in surgery. AJHP 1999;56:1839-87.

[15] Bratzler DW, Houck PM, Surgical Infection Prevention Guideline Writers Workgroup. Antimicrobial prophylaxis for surgery: an advisory statement from the national surgical infection prevention project. Am J Surg 2005;189(4):395-404.

[16] Kocak I, Ustun C, Emre B, et al. Antibiotic prophylaxis in laparoscopy. Ceska Gynekol 2005;70(4):269-72.

[17] Cormio G, Di Fazio F, Lorusso F, et al. Antimicrobial prophylaxis in laparotomic gynaecological surgery: a prospective randomized study comparing amoxicillinclavulanic acid with cefazolin. J Chemother 2002;14(6):618-22.

[18] Johnson N, Barlow D, Lethaby A, et al. Surgical approach to hysterectomy for benign gynaecological disease. Cochrane Database Syst Rev 2006;(2): CD003677. 